\title{
New Requirements of Ideological and Political Education under the Background of Economic Globalization
}

\author{
Tianfu Lin \\ School of Marxism, Minjiang University, Fuzhou 350108 China. \\ 151667434@qq.com
}

\begin{abstract}
With the development of multi-polarization and economic globalization, competition among countries is also intensifying, especially in the field of ideology, where competition is more complex and secluded. In order to master right of speech and occupy the commanding heights of ideological and public opinion, the struggle in the ideological and political field will become more intense. Under the condition of economic globalization, the work of ideological and political education must constantly adapt to the various complicated situations. By strengthening patriotism, marxist theory as well as ideology and politics education, cultivating national spirit and innovating the way of education, the educatees can better accept the content of the knowledge transfer of the educators, and the educators can make full use of the Internet to carry out the ideological and political education.
\end{abstract}

Keywords: economic globalization; Ideological and Political Education; New requirements.

\section{经济全球化背景下思想政治教育的新要求}

\section{林添福}

闽江学院 马克思主义学院, 福州, 350108, 中国

摘 要: 随着世界多极化、经济全球化趋势的不断发展, 各国之问的竞争也日益加剧, 特别是 意识形态领域的竞争更为复杂和隐蔽, 为了抢夺话语权, 抢占思想舆论制高点, 思想政治领 域的斗争将更趋激烈。面对经济全球化条件下出现的各种复杂情况, 思想政治教育工作必须 不断适应变化了的环境, 通过加强爱国主义教育, 培育民族精神, 加强马克思主义理论与思 想政治教育, 创新教育的方式方法, 使受教育者接受教育者传播的内容, 并充分利用网络开 展思想政治教育。

\section{关键词: 经济全球化; 思想政治教育; 新要求}

\section{1. 充分认识经济全球化过程中思想政治教育的重要价值}

在经济全球化带来的各种思想文化和价值观念的冲击下，马克思主义的影响力受到很大的冲 击, 一些非马克思主义的思想对人们产生了一定的消极影响, 而且有一些人对马克思主义比 较漠视, 没有充分认识到马克思主义思想的重要性, 这就迫切需要强化马克思主义理论教育。 展望未来, 我们要站在时代高度去寻找新的应对方法。

1.1 在经济全球化进程中, 必须坚持马克思主义意识形态的地位不动摇。

这是就马克思主义的基本原理、基本观点和基本方法而言的。而随着时代的发展和历史条件 的变化, 马克思主义创始人针对特定历史条件的一些具体论述可能不再适用, 而新的实践又 会提出新的问题, 需要我们去认识、去解决, 这就要求我们在坚持马克思主义基本原理的基 础上, 不断地在实践中丰富和发展马克思主义。在当代, 加强马克思主义理论教育, 就是要 用中国特色社会主义理论体系深入开展理想信念教育。针对社会热点难点问题, 从理论和实 践结合上做出有说服力的回答。在重大思想理论问题上划清是非界限、澄清模糊认识, 有力 抵制各种错误和腐朽思想影响。经济决定政治, 经济不可能脱离政治。经济全球化带来的不 
只是对经济的影响, 政治、文化等也都随着经济全球化进程而受到一定程度的冲击和影响。 经济基础决定上层建筑, 意识形态也不可能脱离于一定的经济之外而存在, 政治也不可能摆 脱一定的意识形态而存在。为此, 我们要保持清醒的头脑, 提高马克思主义意识形态的凝聚 力、吸引力、战斗力, 认清经济全球化进程中还存在诸多不利因素, 坚决抵制西方文化侵略 中腐朽意识形态的糟粕, 增强自身免疫力。要实实在在地做好意识形态领域的工作, 就要搞 好经济建设, 努力促进生产力的发展。消除封建主义意识形态残余毒害和资产阶级意识形态 的不良影响, 搞好意识形态领域的工作, 也同样必须服务于经济建设大局, 绝不允许因任何 因素而干扰到经济建设这一中心工作。苏联解体、东欧剧变的历史教训警示我们, 必须加强 在意识形态领域的主动权, 坚持马克思主义意识形态在思想政治教育中的一元主导地位, 只 有这样, 才能抵制资本主义意识形态的侵袭, 坚持马克思主义的意识形态, 为最终实现共产 主义奠定思想基础。

1.2 在经济全球化进程中, 要提高对意识形态安全艰巨性的认识。

在革命与建设事业上, 对意识形态领域的争夺是关系到社会主义建设成败的重大问题, 社会 主义和资本主义两大阵营和两种思想体系一直以来就在意识形态领域存在着激烈的争夺。资 本主义国家为了获得经济利益, 往往通过思想渗透不断向外进行扩张和掠夺。西方资本主义 国家利用经济全球化这一大势所趋, 依靠自身强大的经济实力加紧对社会主义国家进行意识 形态渗透。在多样化的社会思潮中, 把其他思潮都当作异己来否定, 也同样会阻碍社会的创 新和发展。海纳百川, 有容乃大。我们应当在坚持马克思主义意识形态的主导地位的同时, “尊重差异、包容多样” , 用社会主义的意识形态来引领和整合其他各种社会思潮, 以形成 以马克思主义思想一元为指导的多元社会思潮相互包容、共同发展的格局。除极端的社会思 潮必须被否定外, 允许各种社会思潮的百花齐放、百家争鸣。在开展意识形态教育时, 我们 要主要教育形式和方法的改进和创新, 灌输教育固然必要, 但有时候会造出事半功倍的效果, 我们需要挖掘人们乐于接受的方法与和式进行宣传教育, 使他们在潜移默化中提高对主流意 识的认同。这就需要思想政治教育工作者不断进行方式方法的创新, 增强人们对马克思主义 意识形态的认同感, 摒弃脱离时代要求的观念和各种错误意识, 适应时代的发展变化而不断 的地发展变化, 坚定政治信念。尽管经济全球化为各国提供了经济发展和资源配置的有利环 境和条件, 但实际的情况是, 全球资源配置的成果在发达国家和不发达国家进行着不公正、 不公平、不合理的分配。事实上，伴随经济全球化进程的是发达国家和不发达国家的差距拉 大, 世界上两极分化日益加剧。应该说明的是, 这种后果并不是经济全球化的直接结果, 而 是经济全球化在这种特定国际经济关系下的必然后果。因此, 我们抨击的不是经济全球化本 身, 而是支撑这种经济全球化的世界经济关系的弊端。对这些问题, 我们应该运用马克思主 义基本理论和科学方法, 研究经济全球化变化的新情况和新问题, 把握世界经济、政治格局 的变化与支撑国际经济全球化的经济关系之间的内在联系。应该看到, 经济全球化是社会生 产力高度发展和科学技术突飞猛进的结果, 是人类文明进步的巨大成就, 但是世界经济关系 的资本主义性质却极大地消解和扭曲了人类文明进步的巨大成就, 造成世界经济发展的新的 异化现象。

\section{2 在经济全球化中创新和充实思想政治教育的内容}

面对经济全球化条件下出现的各种复杂情况, 思想政治教育工作必须不断适应变化了的环境, 充实思想政治教育的内容, 使人们认识到, 在经济全球化进程中, 经济的全球化并不能必然 导致政治的全球化, 更不能产生政治的一体化, 民族国家仍然是国际社会的主要行政主体, 也不会伴随着经济的全球化而消失。加强爱国主义教育, 培育民族精神, 才能利用经济全球 化的规则趋利避害, 确保我国的经济安全, 促进经济的快速持续发展, 充分利用经济全球化 的良好契机, 实现民族的富强与振兴。 


\section{1 对经济全球化的后果和影响应该有全面的清醒的认识。}

经济全球化导致的不只是世界经济格局的变化, 而是也引致世界政治、社会、文化格局等多 方面的变化。对待这些变化, 要全面地、系统地看待和认识, 不能片面地、孤立地看待和认 识。首先, 应该看到, 经济全球化作为人类文明进步的结果, 我们应该积极推进它的进程, 并借此机会吸收世界上先进的科学技术、管理经验以及先进的思想和文化。因为这种进步和 发展, 并不是资本主义的专利而是人类文明的财富。其次, 还应该看到, 在经济全球化的进 程中, 要结合本国的实际, 有辨别地吸收和利用经济成就, 不能盲目排斥也不能全盘引进, 特别要注意经济全球化过程中，西方社会的价值观、伦理观、人生观及社会观对各国社会制 度和思想观念、意识形态的冲击。当前, 西方发达国家借助它们在世界政治格局中的强势地 位, 在世界范围内强力推行它们的政治观和价值观, 极力推动世界政治的单极化或单边化。 它们借助经济全球化中的强势和优势，大肆地进行西方文化和意识形态的渗透。政治上的强 权和思想文化领域的渗透, 使世界政治格局和思想文化领域的冲突变得更为尖锐和更加复杂, 世界上反对霸权主义的斗争呈现出错综复杂的新态势。进行有实效的、有针对性的马克思主 义理论与思想政治教育, 就必须深入研究世界经济关系变化的实质, 考察由此引起的世界政 治、文化、道德、社会等等领域发展的新变化, 还要考察经济全球化对国家主权、国家利益、 国家安全等方面的影响。这些教育对所有的大学生都是十分必要的。

\section{2 在经济全球化中加强和创新爱国主义教育。}

重视爱国主义教育, 强调爱国主义是民族精神的核心, 高扬爱国主义精神是最大限度地凝聚 和动员全民族的力量为振兴中华而奋斗的必然要求。经济全球化时代，有些人极力鼓吹政治 一体化和文化一体化，企图借经济全球化推行西方的政治制度和价值观念，损害别国的主权 和尊严。我们应该谨记主权国家仍然是国际社会最重要的行为主体，国家之间的利益争夺仍 然是国际斗争的焦点, 主权国家仍然是国家利益的代表。国家主权是国家独立自尊的象征, 国家主权原则依然是处理国际关系的基础，任何急于超越国家主权的观点与行为都是违背现 实的、有害的。对于爱国主义教育问题, 国内外出现了一些让人担忧的新论调, 认为爱国主 义过时了，当前没有进行爱国主义教育的必要等等。这些论调影响、模糊甚至动摇了对爱国 主义教育的必要性和重要性的认识。新时期, 爱国主义教育也要创新, 必须把握时代脉搏, 赶上时代的步伐。我们不仅要在观念上创新, 而且还要在爱国主义教育内容上创新。不能只 停留在枯燥的口头说教上; 要从娃娃抓起; 不要只注重形式; 要树立爱国主义教育的典型, 通过爱国主义教育的活教材提高人们的感性认识, 使思想不断升华, 从心底情不自禁地燃起 爱国之情; 要加强爱国主义教育基地建设，并使其制度化、法制化。爱国主义是中华民族的 优良传统，是中华民族自强不息、自立于世界民族之林的强大精神动力，是推动我国社会历 史发展的精神支柱。爱国主义体现了人民群众对自己祖国的深厚感情，反映了个人对祖国的 依存关系，是人们对自己故土家园、种族和文化的归属感、认同感和尊严感、荣誉感的统一。 每个人来到这个世界, 都要在社会中生存, 都要获取生存发展的物质条件, 都要寻求慰藉心 灵的精神家园, 这一切首先得之于祖国。爱国是每个人都应当自觉履行的责任或义务. 是一 个民族的聚合剂，是一个族群认同的根基。

2.3 培育民族精神，重视民族文化教育，增强民族自豪感。

思想政治教育在中国的发展, 有社会主义的政治、经济做保证。思想政治教育符合我国国情, 以社会主义文化作支撑。思想政治教育离不开中华民族文化环境，是中华民族文化的一个不 可或缺的重要组成部分，体现民族文化特色，以其特有的形式和内容，为民族的振兴提供强 大的精神动力。

民族精神是民族文化的核心和灵魂, 是一个民族赖以生存和发展的精神支柱。弘扬民族文化、 激发人们对民族文化的热爱，有助于培养公民对民族文化的认同感和自豪感，使其在文化、 精神理念中找到自己的生命所在。因此，大力弘扬和培育民族精神，就是铸造中华民族的精 神支柱, 为中华民族的生存和发展强基固本。弘扬和培育民族精神, 是全面建成小康社会、 进行社会主义现代化建设的重要保证, 是实现中国梦的保证。因为民族精神能够凝聚起全党、 
全国各族人民的力量, 形成强有力的向心力, 把全国各族人民聚集在党的周围, 全面建成小 康社会, 加快推进社会主义现代化的进程, 建设社会主义精神文明的重要内容。一个民族, 没有振奋的精神和高尚的品格, 不可能自立于世界民族之林。中华文化博大精深、源远流长, 经过数千年的历练, 已成为中华民族赖以生存的精神食粮, 为世界文明做出贡献。然而, 在 经济全球化进程中，各种外来的文化正在与民族文化发生激烈碰撞，不同文明之间的冲突与 融合格外频繁。面对纷繁复杂的外来文化, 我们的民族文化该走向何方? 张岱年先生认为: “一个独立的文化, 与另一种不同类型的文化相遇, 其前途有三种可能: 一是孤芳自赏, 拒 绝交流, 其结果是自我封闭, 必将陷入衰亡; 二是接受同化, 放弃自己原有的, 专以模仿外 邦文化为事, 其结果是丧失民族的独立性, 将沦为强国的附庸; 三是主动吸取外来文化的成 果, 取精用宏, 使民族文化更加壮大。”由此可见, 我们需要对各种文化进行批判性的选择, 吸收外来文化的精华，不断创新。面对经济全球化，不能丧失民族精神。一个在文化上自卑、 对自己文化缺乏自信、不热爱自己文化的民族，一个缺少民族精神、没有民族自豪感的民族 注定要在竞争中失败。因此, 培育民族精神具有使国家发展、民族复兴的重大战略意义。

\section{3 在经济全球化中积极改进思想政治教育方式方法}

思想政治教育方法, 是教育者在引导受教育者的思想和行为朝向教育目标的过程中所运用的 方法, 是教育者与受教育者之间的纽带。在 “以人为本” 教育理念的指导下, 在人的主体意 识和个性追求不断增强的情况下, 思想政治教育者必须不断改进、探求多种教育方法, 结合 教育对象主体性不断增强的特点, 多采用启发式、辩论式、讨论式等方法, 深入到教育对象 中间, 建立与他们进行交流的平台, 及时掌握人们的思想动态, 引导、鼓舞、关心和帮助教 育对象，真正做到教育 “以人为本”，使思想政治教育深得人心。

3.1 加强和改进马克思主义理论与思想政治教育。

经济全球化背景下, 如何加强和改进马克思主义理论与思想政治教育, 不仅涉及高校思想政 治理论课程教学内容的选择、科研课题的确定问题, 而且还涉及马克思主义理论学科建设的 新概念问题。从学科建设角度来看, 重要的是把握三个基本的要点: 第一, 要着眼于我国经 济社会和科技教育发展的实际; 第二, 要着眼于马克思主义理论的发展和创新; 第三, 要具 有世界眼光, 把握世界思想、文化和道德发展的前沿, 认识到世界文明的多样性是人类社会 的基本特征, 是人类文明进步的重要内容。在马克思主义理论学科建设中, 要研究和理解这 一学科同马克思主义和思想政治理论有关学科, 如马克思主义哲学、政治经济学、科学社会 主义、伦理学、法学、政治学等学科的关系。就马克思主义理论学科的内容来看, 它同马克 思主义理论有关学科的内容是有密切联系的。马克思主义理论学科建设, 无疑要深入研究马 克思主义的科学原理和科学精神, 深入研究马克思主义的历史、理论与现实发展。

3.2 优化思想政治教育方法，使受教育者接受教育者传播的内容。

单一的思想政治教育方法, 会让受教育者对思想政治教育内容感到枯燥乏味, 从而在接受过 程中产生抵触情绪。马克思主义认为: “敉开自然物质不说, 各种不费分文的自然力, 也可 以作为要素, 以或大或小的效能并人生产过程, 它们发挥效能的程度, 取决于各种方法和科 学进步。”[2]马克思的这一论述也适用于思想政治教育教育过程。面对经济全球化带来的新 形势, 传统的思想政治教育方法, 达不到良好的效果。因此, 思想政治教育应与时俱进, 不 断改进和创新其工作的方式、方法和手段, 努力增强思想政治教育的针对性和实效性。但是, 就马克思主义理论与思想政治教育的教育功能和方法来讲, 学科建设不能仅限于此, 还必然 在两个方面有独特的发展：一是要注重思想政治理论外化的育人功能的研究, 即从提高人的 思想道德素质、推进人的全面发展方面, 深化马克思主义与思想政治相关理论的研究; 二是 要注重对思想政治理论内化的育人方法的研究, 即从教育方法、手段、途径等方面, 加强如 何以科学的理论和精神武装、引导和塑造人的研究。这两个方面研究的密切结合, 是这一学 科的特色所在, 也是推进这一学科建设和发展的根本。同时, 这一学科同马克思主义和思想 政治理论其他各学科、教育学学科等, 也有着显著的交叉性。在马克思主义理论学科建设中, 
还要研究和理解这一学科的外延问题。实际上, 这一学科研究的课题和探索的问题, 涉及社 会各个方面和不同群体。社会各个领域都存在着人的思想政治素质提高和人的全面发展的问 题, 也都存在如何用科学理论和精神武装、引导和塑造人的问题。无论在理论外化的育人功 能上, 还是在理论内化的育人方法上, 不同领域和不同群体显然有着不同的规定, 据此形成 这一学科研究的不同方面和不同内容。在高校进行的马克思主义理论与思想政治教育, 主要 是以大学生这一特定群体为对象的, 这是高校思想政治理论课程中学科建设的特定方面和特 定内容。但也应该看到, 高校思想政治理论课程的建设和发展, 是马克思主义理论与思想政 治教育学科形成的起点, 也是这个学科发展的基础。因此, 高校思想政治理论课程建设是这 一学科建设的最重要的部分, 也是规范这一学科建设的重要基础。以高校思想政治理论课程 建设为切入、为内涵, 是马克思主义理论学科建设的根本所在。

3.3 在经济全球化中充分利用网络开展思想政治教育。

在经济全球化的浪潮中, 网络充当了一个关键又特殊的角色。网络化不仅是信息社会在技术 上的一种表征, 更是人类的一种别样的生存方式, 它对人类的社会化过程产生了重要影响。 网络成为人们获取各种知识和信息的重要渠道, 并且成为一个新的信息传播和教育平台。但 是网上的信息是良莠不齐的, 一些西方国家利用网络对我国进行 “西化” 的渗透, 这就亟需 我们利用网络平台开展思想政治教育。我们要积极、充分地利用互联网为我们服务。要增强 互联网作为思想政治教育资源的意识。由于各种信息能够在因特网上自由地流动, 这就为思 想政治教育进入互联网提供了便利, 也为用户轻松汶览思想政治教育内容提供了现实的可行 性。思想政治教育可以充分利用这个包罗万象的信息资源, 挖掘有用信息, 丰富教育内容, 为受教育者提供更具说服力、更科学的思想政治教育内容。要充分利用网络带来的机遇, 大 力抓好思想政治教育进网络的工作。思想政治教育工作者要充分利用网络功能, 运用文字、 数据、声音、图形、动画等形式的思想政治教育信息, 引导教育受教育者。还可以利用网络 将报刊、广播、图书、录音、录像等宣传信息发布在网上, 以增强思想政治教育的感染力、 吸引力。高校要充分利用校园网络开展思想政治教育, 发挥网络沟通与交流的平等性、民主 性和自由性的优势, 通过网上聊天、QQ、微信等方式加强与学生的交流, 这样既能倾听学生 的心声, 帮助学生解决一些心理疑惑, 又能对事关政治方向和敏感性的社会问题及时地做好 與论导向，实现思想政治教育的目的。

在实现中华民族伟大复兴的历史征程中，马克思主义理论与思想政治教育要十分关注经济全 球化及其引发的一系列新变化和新问题, 要认清经济全球化进程中思想政治教育面临的机遇 和挑战, 以高度的责任感和紧迫感, 加强思想政治教育工作, 需要思想政治教育者不断提高 自身素质, 深入思考并在实践中不断创新思想政治教育的内容、方式、方法和手段, 努力使 思想政治教育体现时代性、把握规律性、富于创造性，从而不断增强思想政治教育的实效性。

\section{Acknowledgements}

This article is the Fujian Provincial Department of Education 2013 provincial and young teachers teaching project "The Influence of Contemporary Social Thoughts on College Students and the Countermeasures - Taking Fuzhou University as an Example"(Item No. JB13170S) Research Results.

\section{References}

[1]. Zhang Dainian, Zhang Dainian complete works, volume7 [M]. Shijiazhuang: Hebei people's publishing house, 1996, P63.

[2]. The compilation Bureau of the CPC Central Committee Marx, Engels, Lenin and Stalin, Marx Das Capital, volume2 [M]. Beijing: People's publishing house, 1975, P394. 